\title{
EVOLUTIONARY DEVELOPMENT OF 'HINGLISH' LANGUAGE WITHIN THE INDIAN SUB-CONTINENT
}

\author{
Dr. A. N. Salwathura ${ }^{* 1}$ 洒 \\ ${ }^{*}{ }^{*}$ Senior Lecturer I, Department of Hindi, University of Kelaniya, Sri Lanka
}

DOI: https://doi.org/10.29121/granthaalayah.v8.i11.2020.2278

Article Type: Research Article

Article Citation: Dr. A. N.

Salwathura. (2020). EVOLUTIONARY DEVELOPMENT OF 'HINGLISH' LANGUAGE WITHIN THE INDIAN SUB-CONTINENT. International Journal of Research GRANTHAALAYAH, 8(11), 41-48. https://doi.org/10.29121/granthaa layah.v8.i11.2020.2278

Received Date: 01 November 2020

Accepted Date: 24 November 2020

Keywords:

Official Language

Hinglish

British Raj

Colonial Period

Standard Hindi

\section{ABSTRACT}

Hindi is the official language of India which is spoken by around 350 million of people in India. Hindi and English have an incestuous relationship ever since India became colonized. Since then, Hindi began to mix with English and became famous as 'Hinglish' in Indian society. 'British-Raj' is considered as the first Hinglish word which was used in the colonial period and now Hinglish has become a common phenomenon practice in India in day-to-day life. Due to the popularity of Hindi movies and television, Hinglish has been spread beyond the metropolitan areas in India. Therefore, it is expected to examine the impact of using Hinglish by Hindi speaking people in India on the existence of standard Hindi language. The language spoken in North India and the language used in media were utilized as primary resource. Books, magazines, journal articles related to Hindi language were used as secondary resources. This paper highlights that Hinglish has been acquired a big demand in Indian society and now it is hard to eliminate this trend which has largely affected the day-to-day communication of Indians. This paper emphasizes that the extensive use of Hinglish by the Hindi speaking people in India has become a huge challenge for the existence and the values of standard the Hindi language.

\section{INTRODUCTION}

Modern 'HINDI' language would definitely be regarded as the National Official language of 350 million Indian population. Due to misunderstanding of certain group of people on the issue of Official language, a solution was created by making 05 sub languages and 18 more provincial sublanguages in respect to usage by the civilians in India. Furthermore, English was given priority in government and commercial activities for an extra period of 15 years as the official communication language even after gaining Independence from the British on $15^{\text {th }}$ August 1947. (Official language circular - 1963.)

Accordingly, when we recollect and consider the background status of languages, in the era of 'colonial' India, it is a well-known fact that Hindi language have had a close relationship, coordination and also had an impact too with English language, than almost all the other provincial languages, throughout Indian sub-continent. This detailed analysis is based and centered upon how Hinglish language certainly effect the nature of present standards on Hindi language.

Hinglish could be regarded, highlighted and well defined as a combination \& mixture of both Hindi and English languages

(C) 2020 The Author(s). This is an open access article distributed under the terms of the Creative Commons Attribution License, which permits unrestricted use, distribution, and reproduction in any medium, provided the original author and source are credited. 
A blend of Hindi and English, in particular a variety of English used by speakers of Hindi, characterized by frequent use of Hindi vocabulary or constructions.

- English Oxford Living Dictionary ${ }^{1}$

A mixture of the languages Hindi and English, especially the type of English used by speakers of Hindi Cambridge Dictionary. ${ }^{2}$

A variety of English incorporating elements of Hindi

Collins English Dictionary. ${ }^{3}$

A language that combines elements of English and Hindi or other South Asian languages Macmillan Dictionary. ${ }^{4}$

Even a report in Bollywood Life described Hinglish as a "bastard child" produced by the "systematic rape of both English and Hindi.". 5

Anyway, the very first Hinglish word that is still supposed to have in Records could be termed as, 'BRITISH RAJ'. British Raj is used to express the term for British Empire. From the Colonial era, up to today, the British period is being introduced by the term, British Raj.

When we do re-consider the Evolution and Expansion of Hinglish language, there are written evidences which could be listed as follows.

- The first usage in literature - Ayodhya Prasad Khathri (1857-1905) Gazal ${ }^{6}$

- Usage of Devyani Chaubal and Shobha De for Column letters.

- Preparation of 'The Queen's Hinglish: How to Speak Pukka Dictionary'. B. K. Mahal in 2005

- In the year 2011, in order to elaborate convenience in cooperative coordination for almost all official activities, Official Language Department of Indian Home Affairs Ministry issued a Circular ordering to use Hinglish words instead of Hindi language terms which will ease pronunciation, according to the new techniques.

- In the same year (2011), publication of 'Chutnefing English: The phenomenon of Hinglish' by Rita Kothari and Rupert Snell.

- In the year 2015, two novels being edited, namely, 'Beautiful Roes' by Swapna Rajputh and 'Kuch Kahi Kuch Ankahi' love stories by Richa Dewsar

At present, it is clearly visible and understood that almost all the popular mass media, including cinema, television, social websites and digital media with Indian urban society too have come to very close impact with modern Hinglish language. Within such a setting, it is clearly visible of the unfavorable and unethical impact on standard Hindi language by the modern and recently evolved Hinglish language.

The aims and objectives of this current study and analysis could be listed precisely under 03 headings, as follows.

- The study on direct effects and its results of Hinglish language to the modern standard Hindi language.

- The study on these effects of Hinglish language to the sustainability of modern standard Hindi language.

- The ways of controlling methods and neutralization of its different effects. Suggestions to maintain the stability of modern standard Hindi language.

This research or analysis is being performed in an environment where study and teaching of Hindi is conducted as a foreign language. Therefore, the base had been the usage of Hinglish language in print media, broadcasting

1 English Oxford living Dictionary, www.oxfordlearnesdictionaries.com

2 Cambridge Dictionary, dictionary.cambridge.org

3 Collins English Dictionary, www.collinsdictionary.com

4 Macmillan Dictionary, www.macmillandictionary.com

5 Bollywood Life, official website. www.ibtimes.com

6 Sharma, Dr. Jayanta Kar (2015) Hinglishisation of English: Hinglish, The Language of 21st Century, IJELLH, International

Journal of English Language and Humanities, Indexed, Peer Reviewed \& Refereed Journal, Vol. III Issue VIII, p. 330

International Journal of Research -GRANTHAALAYAH 


\section{Dr. A. N. Salwathura}

sector, films and TV including social media. The research problem was totally based upon Hinglish language in broadcasting, films and TV and social website media as primary resources while E-mail, letter scripts, magazines and video as secondary resources.

Related to the research on usage and expansion of Hinglish language, the main cause to its popularity could be none other than its simplicity with easy absorptive power by the Hindi speaking society.

The main reason behind the speedy propagation of Hinglish language among the Indian society could be its intimate affinity to English wordings which has paved the way towards English language and its culture.

This close affinity of Hinglish language towards English language and its culture, has the distinction being well respected towards the constant usage of Hinglish language with very much close connection to English language wordings.

The well observed 'Trend', towards close affinity with Hinglish language by majority number in Indian societies featured them easily, being well regarded and respected by the English-speaking generations in the last lap of Colonial era within India.

I hereby, list down the zones \& sectors in which Hinglish language being very popularly touched and used by the present generation.

- Sub urban and Urban areas throughout the Indian- subcontinent.

- Schools, Colleges and Higher Educational Institutions with English medium curriculum stream.

- Media of Cinema, TV, Broadcasting sectors including almost all the popular Social Websites.

- Provinces with Indian diaspora.

The popular usage of Hinglish language could easily be well heard and observed within common society throughout its professional advertising of distinct and vivid propaganda activities. In any country, their social language is directly and strongly related to professional advertising. It is very correct to pen it here that professional advertising is the key partner which symbolizes direct effect in usage of language.

Usage of Hinglish language could always be very well heard and observed in almost all print media, audio-visual media and professional propaganda advertising, specially due to its specific attractiveness towards consumers and customers of vivid items and articles.

Examples:

Domino's Pizza - Hungry kya
Pepsi - Ye dil maange more
Lays - Pal banaye magical
Hero MotoCorp - Hummein hai hero
Close up - Kya aap close up karte hain?
Sun Silk - Come on girls, waqt hai shine karne ka
Coca Cola - Life ho to aisi
Mac - What your bahana is?
Maggie - Taste bhi health bhi
ICICI banks - No chintaa only money

Accordingly, in one way, the usage of Hinglish language covering print media, audio-visual media and social websites in market advertising, has been a reason why the consumers are being attracted to mosaic items.

On the other hand, the members of present younger generation, who are being easily attracted to this Hinglish (HYBRID) ${ }^{7}$ language in brief, with the short messages which bring ample publicity for its communication via less complex simpler wordings. Everyone regards it as a convey of the fruitful message, with lesser amount of words and as an instant absorptive media too.

The following examples will definitely speak \& describe lot about the 'language condition' of Hinglish language and real detailing of its 'hybrid' nature.

- Main tujhe call kar raha tha, but tera phone switch off tha. Phone recharge karaale.

- Ek new shop open hui hai mere colony main.

${ }^{7}$ India has recently seen flexibility of its native tongue first hand. Hinglish, a hybrid of Hindi and English, has made a name for itself as an emerging language in the country.

The Hinglish Phenomenon, unitedlanguagegroup.com

International Journal of Research -GRANTHAALAYAH 
- Bhai main abhi just apple kha raha tha ki mere mom dad mere room main enter hue aur mujhe padhne ke liye convince karne lage

- Ye game download karke ise install kar liyo. Let's see ki tere mein ye game kitna fast chalta hai. Because mere computer ki processing speed kaafi slow hai. Mera luck bahut achha hai. Finally, ye game ekdum mast chal raha hai.

Namely, Star TV, Sony, Zee and Colors which were being invented, created and marketed with satellite techniques in the 1990's; MTV, Duradarshan channels/ FM channels, do produce many popular programs consisting dialogues with Hinglish language which seems to be very close and intimate, specially to the present young generation. A very popular FM channel in India namely, 'Radio Mirchi' introduces as its 'Pay offline' in Hinglish language. (Example: mirchi sunnewale always khush)

It is very correct to state here that the 'Official language', of almost all the Private FM and TV channels is also considered as this 'Hybrid' Hinglish language. At present, Hinglish language is no longer used only for human verbal communication. Other than the Roman letterings, a specific Colour Columns referred as 'Romenagari are also being created.

Examples:

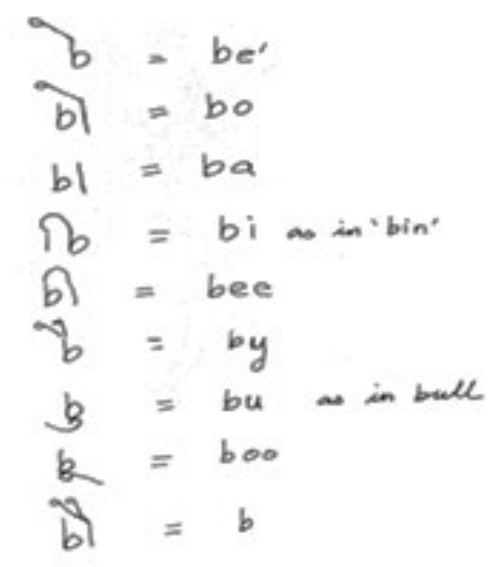

Assurance of critics with responsibility, the Internet and Hinglish language would be regarded as mutual friends who could never be separated. ${ }^{8}$ They are tightly bonded and mutually reinforced with broad inter-relationship too.

Here are a few of the popular illustrations with its common statements used in social media.

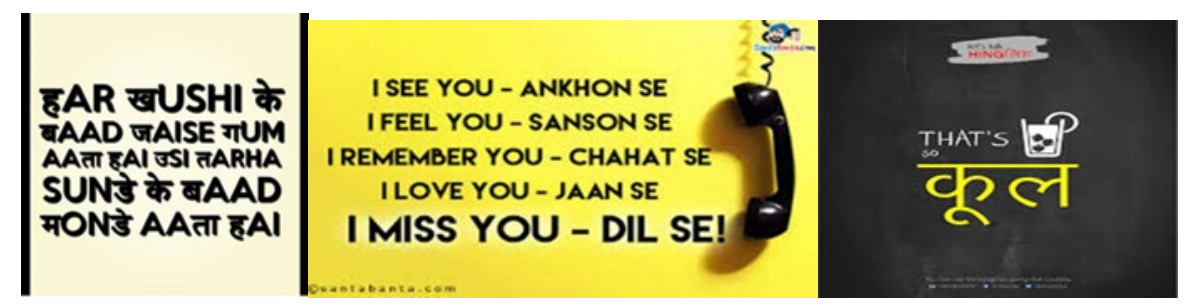

Hybrid Hinglish language has also entered into Indian literature with inclusion of Roman letterings as very well denoted above.

Other than that of the two Hinglish novels written with Roman letterings, a fabulous and awesome novel published, namely Midnight's Children ${ }^{9}$ in 1981 by a British Indian author Salmon Rushdi was honored with Man

${ }^{8}$ The relationship of Internet and Hinglish is again mutually reinforcing.

Nema, Nidhi \& Chawla, Jagtar Kaur 2018 The Dialectics of Hinglish: A Perspective. p. 44

${ }^{9}$ Midnight's Children is a 1981 novel by British Indian author Salman Rushdie. It deals with India's transition from British colonialism to independence and the partition of British India. It is considered an example of postcolonial, postmodern, and magical realist literature. The story is told by its chief protagonist, Saleem Sinai, and is set in the context of actual historical events. The style of preserving history with fictional accounts is self-reflexive.

International Journal of Research -GRANTHAALAYAH 


\section{Dr. A. N. Salwathura}

Booker Prize too, which had a complex mixture of English and Hindi language letterings \& wordings on. Furthermore, this award winning novel in 1981, did not contain any of the foot notes nor indices too. (Examples -Arre Baap, ekdam, nasbandi, phu-a-phut, dhoabn, rakshasha, fauz, jailkhana, badmaash, baap-re-baap, pyar kiya to darna kya, zenana, sarpach, bhel-puri)

Educated critics do state as their viewpoints, that the author Rushdi had definitely opened and well cleared up a new avenue for this popular Hybrid Hinglish language. This again, has made the present Indian generation stepping into and promote this Hybrid - Hinglish language with proper lively nature and sensible feelings too. ${ }^{10}$

From the decades of 70s and 80s, Hindi cinema [Bollywood cinema], has certainly accepted the usage of Hinglish language which is functioning as its sole art media within the sub-continent of India. Throughout a Bollywood film, commencing from its titles via dialogues in the script and up to its music, each and every part is happened to be either in pure Hinglish language or a deviation of its hybrid nature. The effects of it are clearly visible in usage of languages which are remarkably prominent. In almost all the films in Bollywood cinema, nomenclature in its titling had permanently transformed into this Hybrid Hinglish language too.

Examples: English Vinglish, Dear Zindgi, Apna Sapna Money Money, Jab We Met, Love Aajkal, Thoda Pyar Thoda Magic, Desi Boys, Pyar Mein Twist, Shadi Ke Side Effects, Shuddha Desi Romance, Raincoat, Pink

Really, when we do consider and have a close observation on parts of songs, common usage of this extra popular Hinglish language with hybrid nature throughout the songs are clearly visible.

- Saree ke fall sa kabhi match kiya re - Kabhi chhod diya dil kabhi catch kiya re - R. Rajkumar (2013)

- Ladki beautifull kar gai chull - Kapoor and Sons Since 1921 (2016)

- But pappu can't dance saala - Jaane Tu Ya Jaane Na (2008)

- Tere Liye hi toh signal tod tad ke, aaya dilli wali girlfriend chod chad ke - Ye Jawani Hai Divani (2013)

- Golmaal, golmaal, everything's gonna be golmaal - Golmaal Returns (2008)

Accordingly, the precise, plain and prevailing truth and view of 'language visharadas' is really the gradual transformation of Hinglish language expanding to the state of communication at present ${ }^{11}$ but Hinglish language was only in the state of a written language, before 2 and $1 / 2$ decades. (around 30 years or so).

Why and how this was possible and happened in India?

It is very well understood that in the recent past, within a society in India which Likes or Dislikes and Comments were the only mode of communication in social media, a very high propagation of Hinglish language comparatively had been with so much of ease and could not have been avoided too. This is more evident, observed, heard and prevailing in almost all the mass media, cinema, all sectors in sales and marketing, education, politics and in the field of governance. Currently, Hinglish language has been an essential device throughout Indian sub-continent in all of the above mentioned spheres.

More than the self-mother tongue, a way and obvious means to be mixed with an internationally acclaimed language as English, have made it clear to be more popular and relevant in usage of Hinglish language in regard for the protection and safe-guarding themselves within the more elaborated present generation.

This is definitely a modern way of concepts and thoughts which have been created in the minds with developing attitudes towards a longevity within the society of present generation itself. Within this actual mode of background, widely spread Hinglish language will be a 'Great Challenge' in the near future to the survival of present standard HINDI LANGUAGE throughout Indian-subcontinent.

Problems [or difficulties] could be listed, which are being created by consistent usage of Hinglish language in different communities within the Hindi speaking society.

1) 'Hinglish', could be the most appealing form of language with the interaction of new technical developments and globalization. As a result, present generation gets retarded in the study of genuine and pure standard Hindi language, which automatically be limited only to books and literature published some time back.

2) Mainly due to the above reason, the ability to grasp the vast knowledge in Hindi literature which is regarded as composed in exceptional standard Hindi language will be degraded and devalued.

${ }^{10}$ Whatever the critical viewpoint, Rushdie opened up new avenues for the language of hybrid Hinglish to comprehend the Indian context and sensibility.

Nema, Nidhi \& Chawla, Jagtar Kaur 2018 The Dialectics of Hinglish: A Perspective. p. 46

${ }^{11}$ Dube, Abhay, Final Discussion, Hingilsh Workshop 18-19 August 2014, University of London, sarai.net International Journal of Research -GRANTHAALAYAH 
3) Within the present social background, kindergarten students will be directly exposed to popular Hinglish language. Even modern educationists do accept that this causes harmful effects on their accurate pronunciation of standard Hindi language. ${ }^{12}$

4) Specific letterings as त, थ, ट, ठ related to mother-tongue and nasalized (vowels), nasal sound, non-aspirated and aspirated letterings and correct approach to their pronunciation are mentally deleted. For examples:

- To the letterings of त, थ, $\mathbf{C}$, and $\delta$ commonly $\mathbf{t}, \mathbf{t h}, \mathbf{t}$ and th are being used in present Hinglish language. This clearly neglect the aspirated and non-aspirated divisional demarcation in Standard language of Hindi. In addition, different of dental $\pi$, थ sounds and retroflex $己, \delta$ are not represented in the written forms when writing Hindi words with English characters as $\mathbf{t}$ and th are respectively used in both instances.

- ' 'aankh' (आँख) is supposed to be a nasalized (vowel) wording 'ank' (अंक) is a word with Nasal sound. When such words are being registered with Roman letterings and pronounced as pre-pronunciations, there is always an absolute contrary observed when compared with correct approach of Hindi language pronunciation.

- In standard Hindi language, $\boldsymbol{k a}, \boldsymbol{k i}, \boldsymbol{k} \boldsymbol{e}$ (का, की, के) are being introduced as indicators of genitive (possessive) cases. They are commonly used considering the Feminine/ Masculine and Singular/ Plural differences of the related noun, which is being used immediately after the case indicator. This is the mode of special grammar which is to be strictly considered and genuinely used by Hindi speakers. As usage of English nouns in place of Hindi nouns are permitted and possible with the 'cases' without specific Feminine/ Masculine counter-parts are also being allowed. As a result of this observed extra convenience, it is very free and familiar to use this current way of approach rather than that of the mother-tongue which was its primary usage in Hindi language.

- Apart from the indicator of genitive case kee (की), there is a single preposition that is being used to combine two phrases in reported speech as $\boldsymbol{k i}($ कि). When we indicate it with Roman letterings, we are being forced to use only $k i$ in both the instances. This seems to be another negative effect that standard Hindi language totally faced and effected unfavorably with the evolution of Hinglish language.

It seems to be very unfortunate to neglect the valued mother Hindi language, in most of the common and popular usage of almost all the communicative activities of Hinglish language. Comparatively, very correct grammar and pronunciation of standard Hindi language are being automatically pushed aside and retarded with the introduction of popular Hinglish language replacing the noble status of standard Hindi language which was strictly 'grammarconscious' for more than thousand years or so.

The attentive assumption on analysis of the educationists in regard with the sole structure of Hinglish language could basically be defined as follows:

'Hinglish language would be regarded as a clear hybrid condition of pure Hindi language being the 'Body' and the real English language as the 'Soul" ${ }^{13}$.

Anyway, the following facts could be listed as the direct effects of Hinglish language on pure Hindi speaking communities which seems to be different from each other.

- Even having the ability of consistent usage of Hindi wordings, there is no purpose or necessity of formation of a separate language with English being its counterpart. 'There is no need of a language of that sort' is a strict concept of some of educationists.

- The newly born language had been named as Hinglish language with its main intention being promoting English language which is the counterpart of it.

- Although Hinglish language do use words of English in between, there is no much evidence to highlight the effects of it on Hindi language as Hindi had been in communication with Indian population for more than thousand years or so throughout Indian-subcontinent.

12 Excessive of 'Hinglish' from an early age is now being linked with speech disorders like stammering and 'faulty production of sound' among children.

Expert links Hinglish with poor articulation, times of India, indiatimes.com

${ }^{13}$ Dube, Abhay, Final Discussion, Hingilsh Workshop 18-19 August 2014, University of London, sarai.net International Journal of Research - GRANTHAALAYAH 


\section{Dr. A. N. Salwathura}

- The specific beauty of Hindi language has never faded off for around thousand years or so, even though usage of many English words or phrases in recently introduced Hinglish language are visible with modern western touch. Popularity of Hinglish language is mainly with the members of younger generation who cannot grasp the value of the standard Hindi language and understand the significance of it.

- Another suggestion is to reconsider and also name Hinglish language as another language like Urdu and Persian in Indian sub-continent.

- Some do criticize Hinglish language very heavily without mercy and suggest banning and prohibiting the usage within civilians of India as from today itself.

There are many assumptions and views about this matter as being listed above. However, as a person who represents a non-Hindi speaking society where Hindi is taught and learned as a Foreign language, my strict conclusion is that there seems to be direct and indirect effects which degrade the sustainability of pure Hindi language. We mainly do study and educate ourselves with historical, modern standard Hindi language and its related noble literature. Hinglish language is concerned only with the purposes of communication, coordination and other necessities in Internet facilities. Language related conditions are combined with structural Hindi language. However, at present, Hinglish language is empowering its sovereignty to each and every division among the different communities of present generation. As a distinct result, in near future modern standard Hindi language would only be limited to Higher Educational institutions surrounding Indian sub-continent. We cannot come to a firm conclusion with the statement mentioning its origin either by concept or usage but we definitely can confirm its bad effects towards the sustainability of modern standard Hindi language.

Even before Hinglish language had approached to this scene of languages in India, we had observed two types of communicative Hindi languages, namely 'pure' Hindi and Hindustani. In Hindustani language there were simple Arabic-Persian mode and Sanskrit-Tadbhava (derivatives) mode, but there was no considerable language diglossia or difference as such. But, when we do analyze the language structure and vocabulary of Hindi language and Hinglish language, we can observe the difference of language diglossia as communicative Hinglish language and written Hindi language.

Therefore, it is very necessary and essential too to take immediate action with definite steps within the administrative government level to maintain the real identity of modern standard Hindi language with immediate declaration of the Hinglish language as its structural mode of communication only.

\section{SOURCES OF FUNDING}

This research received no specific grant from any funding agency in the public, commercial, or not-for-profit sectors.

\section{CONFLICT OF INTEREST}

The author have declared that no competing interests exist.

\section{ACKNOWLEDGMENT}

None.

\section{REFERENCES}

[1] Bhattacharya, Usree (2011) A Case for Hinglish, foundintranslation.berkelely.edu

[2] Chosh, Palash. (2012) The rise of Hinglish; Modern Necessity or Dire Threat to India's Culture and Language, International Business Times, www.ibtimes.com

[3] Coughlan, Sean, (2016) It's Hinglish, innit?, BBC News Magazine

[4] Cox, Patrick (2012) Hinglish: A Case of Reverse Colonization? www.pri.org

[5] Creativeculturerint.com - Bilingual Advertising in a multilingual India

[6] Dixit, Yamini (2005) Indian Award-Winning Advertisements; A Content Analysis

[7] Dube, Abhay, Final Discussion, Hingilsh Workshop 18-19 August 2014, University of London, sarai.net International Journal of Research -GRANTHAALAYAH 
[8] Kothari, Rita (2011) Chutnefying English; The Phenomenon of English, Penguin Books, India

[9] Monga|, Evellyn (2011) Does hinging on Hinglish make business sense? indiatimes.com

[10] Nadi, Srima (2013) The Stat u s of English in Indian Advertisements, IJECT, Vol. 4

[11] Nema, Nidhi and Chawla, Jagtar Kaur 2018 The Dialectics of Hinglish: A Perspective

[12] Paurohit, Jayesh (2013) Effective use of Hinglish in Indian Advertisements, www.afaqs.com

[13] Rahman, Nishath (2015) Hinglish is the New NRI and global language, The Times of India

[14] Sharma, Jayantha Kar (2015) Hinglishisation of English; Hinglish - The language of 21 Century, International Journal of English Language, Literature and Humanities

[15] Sharma, Dr. Jayanta Kar (2015) Hinglishisation of English: Hinglish, The Language of 21st Century, IJELLH, International Journal of English Language and Humanities, Indexed, Peer Reviewed and Refereed Journal, Vol. III

[16] The Hinglish Phenomenon, unitedlanguagegroup.com

[17] Wiley, John (2015) The use of Code-mixing Indian Billboard Advertising, Onlinelibrary.wiley.com 